\title{
TAKING STOCK OF THE NATIONAL ARV PROGRAMME: WHAT EXACTLY HAVE WE DONE?
}

\author{
Fatima Hassan, $B A L L B, L L M$ \\ Attorney, AIDS Law Project
}

On 8 August 2003, the government of South Africa (SA) made a commitment to provide antiretroviral (ARV) treatment in the public health sector. On 19 November 2003, it published the Operational Plan on Comprehensive HIV and AIDS Care, Management and Treatment for South Africa (the Operational Plan). Some $2 \frac{1}{2}$ years later, let us take stock of what is happening.

In June this year, world leaders met in New York at the United Nations General Assembly Special Session (UNGASS) on HIV/AIDS to review whether member states have met certain obligations agreed in the 2001 Declaration of Commitment on HIV and AIDS. While the meeting is politically important, it is bound to offer very little hope to millions of people living with HIV in Africa, South America and Asia who continue to wait for access to treatment. This is because even though there seems to be an international commitment to expand AIDS treatment access, the global rate of access is short of the internationally endorsed universal access goal for 2010, leaving millions without lifesaving care and hundreds of thousands of people with HIV/AIDS facing the prospect of imminent death. According to the World Health Organization (WHO), about 600000 more people gained treatment access in 2005. At that rate, fewer than half of those who need AIDS treatment will have access in $2010 .{ }^{1}$

This is why an international alliance of civil society advocates has called for setting a new global AIDS treatment target of ' 10 by 10' - 10 million people accessing treatment by 2010 . But the international community seems to have gone out of its way to avoid setting explicit global treatment targets that would focus attention on specific outcomes, acknowledge the responsibilities of global institutions as well as countries, and drive accountability. Current negotiations on the 2006 UNGASS Political Declaration suggest that the treatment section is weak, particularly on setting explicit treatment targets.

In SA, the national Department of Health submitted its final Progress Report on the Declaration of Commitment on HIV and AIDS (Progress Report) to the UN for the purposes of this meeting. ${ }^{2}$ But it did so unilaterally and without any significant consultation with stakeholders. The Department excluded the views of civil society, private bodies and health academics, and it has been accused of failing to confer adequately with many partners that have assisted it with implementing the Operational Plan. For example, at a public meeting of the Joint Civil Society Monitoring Forum (JCSMF) held in March 2006, participants and members of the JCSMF were informed of one consultative meeting hastily convened by the national Department of Health on 2 March 2006 to discuss SA's report to UNGASS on progress with the implementation of the UNGASS Declaration of Commitment (2001). At that meeting, civil society and other stakeholders were told to submit comments on the draft Progress Report within a week. But even though some organisations managed to submit short recommendations within a week, those recommendations were subsequently ignored in the final report. The Progress Report has been criticised by many organisations in SA for glaring inaccuracies as well as its attempt to gloss over key shortcomings of SA's AIDS policies. ${ }^{3,4}$ Significantly, the Progress Report fails to include information, data and statistics relating to HIV mortality, prevalence, TB and HIV incidence, ARV patient numbers and ARV treatment targets.

Globally and locally, targets are important. For example, the WHO committed to treating 3 million people in the developing world by the end of 2005. Even though these targets were not met by then, it created the momentum to scale up treatment access in many parts of the world - including in SA and countries that until then did not have domestic capacity to start ART.

The world's leaders have now committed themselves to achieving universal access by 2010. Will they fail? A lot depends on whether this commitment is vigorously pursued by member states at a local level. So far the picture does not look promising. In November last year the International Treatment Preparedness Coalition (ITPC) ${ }^{*}$ issued Missing the Target: A Report on HIV/AIDS Treatment Access from the Frontlines. The report detailed specific barriers and potential solutions to AIDS

\footnotetext{
* The International Treatment Preparedness Coalition (ITPC) was born at the International Treatment Preparedness Summit that took place in Cape Town, South Africa, in March 2003. That meeting brought together for the first time community-based treatment activists and educators from over 60 countries. Since the Summit, ITPC has grown to include over 700 activists from around the world and has emerged as a leading civil society coalition on treatment preparedness and access issues.
} 
treatment delivery in six countries heavily affected by the epidemic (including South Africa) and made recommendations for national governments and multilateral institutions. Six months after the publication of Missing the Target, the ITPC has found progress on several of the barriers to scale-up identified in November. However, deficient national leadership, and slow implementation of reforms remain critical roadblocks to treatment delivery and are costing lives every day in each of the six countries reviewed. ${ }^{1}$

With regard to SA, the ITPC identified the lack of proper leadership coupled with AIDS denialism as the main obstacles to increasing the number of patients on treatment. Other barriers include an acute shortage of health workers, mainly nurses and pharmacists, lack of proper infrastructure, and insufficient access to and promotion of VCT. The report noted that too few children were on treatment.

On a global level, the ITPC called for a new and more effective Global Fund for AIDS TB and Malaria (GFATM) Country Coordinating Mechanism (CCM) as well as sustainable funding for the GFATM, fewer restrictions and more collaboration from the PEPFAR programme including using generics registered by individual states and providing reproductive health services including condom distribution, increased visibility and leadership from UNAIDS and WHO, and greater involvement from civil society in treatment expansion.

\section{WHAT HAS HAPPENED?}

So let us look at what has happened since. In SA, by January 2006, the total number of people on ARV treatment in both the public and private sector was estimated to be about 200000 220 000. About 110000 - 120000 people were purportedly accessing ARVs in the public sector, with an additional 90000 - 100000 receiving it in the private and not-for-profit sectors. (F Hassan and D Bosch - unpublished data, 2006, and F Hassan - unpublished data, 2006. See also Social Cluster briefing, Parliamentary Media 10 February 2006, ${ }^{5}$ where the Minister stated that there were 229 sites treating 117897 patients on ARVs at the end of December 2005. For a more detailed analysis of the Operational Plan see Hassan F, forthcoming publication by Equinet, 'The Provision of ARV Treatment in SA', www.equinetafrica.org). The majority of the approximately 110000 - 120000 patients (both adults and children) receiving public sector care are concentrated in three provinces (Gauteng, Western Cape, and KwaZulu-Natal). Most of the patients in the public sector are women, averaging at about $60 \%$ of all patients. Without the significant contribution of donors such as ARK, MSF and PEPFAR the public sector numbers would be even lower.

At the end of 2005, about 245000 - 300000 children were estimated to be living with HIV. Some experts suggest that on the basis of these figures, about 50 - 60\% need immediate access to ARVs. At present we estimate that only about $10000-15000$ children are receiving ARV treatment, that is about $10 \%$ of the total patients on treatment, while others argue that this figure is substantially lower. In particular, in many smaller and less resourced provinces the number of children on treatment is far below $10 \% .{ }^{6}$ Children therefore continue to be neglected during the planning for the provision of ARVs and HIV care. And the same trend is merging in other developing countries.

In addition, very few men are accessing treatment in the public sector in SA. But in the private sector, men outnumber women on treatment. This is because workplace treatment programmes are generally more available to male workers. Most patients on ARV treatment in the public sector are still receiving care at academic hospitals and so-called hospital 'main sites', with very few patients accessing ARV treatment at non-hospital, rural and remote sites.

What all of this tells us is that accurate numbers are hard to come by. This is because there is no proper Monitoring and Evaluation System (MEtE) in SA. (Clinicians have warned that accurate data are absent on the number of patients on ARVs. For example, there are two separate systems (pharmacy and clinical) for capturing key data, and they rarely agree.) The national Department of Health has confirmed this. ${ }^{7}$ It has admitted that the total number of people receiving ARV treatment is 'not yet known, as the patient monitoring system is not yet able to collect information to this level of detail in a reliable manner ${ }^{17}$ (p. 26) - this some $2 \frac{1}{2}$ years after the Operational Plan was adopted.

Public health experts advise that the failure to have a proper M\&EE system has resulted in provinces being entrenched in a range of different data collection solutions and approaches. According to them even though revised indicators for the HIV programme are available, many of these are not feasible without a facility-based system through which data can be aggregated. The indicators themselves are often confusing and do not follow principles of collecting limited but

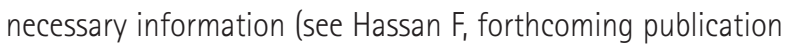
by Equinet, 'The Provision of ARV Treatment in SA').

\section{BARRIERS TO IMPLEMENTATION}

As in most other developing countries, human resources are a major barrier to the speedy implementation of prevention and treatment programmes in SA. Even though the national Department of Health has finally released its Country Plan for Human Resources in Health (HRH Plan) it remains to be seen how the plan will address real shortages in the short, medium and long term. ${ }^{8,9}$

Notwithstanding an initial forecast made to Parliament by the national Department of Health in February 2004 that the process of drug procurement would be completed by June 2004 , the award of the drug tender was only announced on 2 March 2005, some 13 months after the drug procurement process commenced and more than 16 months after the Operational Plan was adopted. ${ }^{10}$ The tender is worth over R3.7 billion and expires in 2007. But serious problems may arise with drug supplies. This is because, unlike the Brazilian government, the SA government is not planning ahead. For 
example, it is not taking steps to ensure a sustainable supply of a range of key drugs. There appears to be very little government concern that there is only one supplier of Kaletra. The same is true of efavirenz (marketed by MSD as Stocrin) even though a licence has been issued to Aspen Pharmacare to manufacture a generic version, it is still not yet registered for commercial use. If more competition truly existed, we would also witness a downward pressure on prices. This is important given that in terms of value, two pharmaceutical companies, Abbott Pharmaceuticals and MSD, have secured a substantial percentage of the tender (more than 50\% jointly). Therefore, if the prices of key drugs are not brought down through generic competition, government will continue to waste valuable resources. In addition, without multiple suppliers sustainable supplies of key drugs will be jeopardised. For example, since the inception of the Operational Plan there have been several reports regarding problems with drug availability in various parts of the country (Gauteng, KwaZuluNatal and Mpumalanga in particular). The supply of efavirenz has been beset with problems of repeated stock-outs.

On treatment regimens, while there is consensus among HIV clinicians in the private sector that $d 4 t$ should be removed from the first-line treatment regimen and replaced with tenofovir (which has fewer side-effects), this has not happened because tenofovir is not yet registered by the Medicines Control Council (MCC). It is unclear when it is likely to be registered or why the fast-track process that it has been subject to has not materialised. Clinicians have warned that this delay is undermining the possibility of using optimal treatment regimens in the public sector.

In order to achieve universal access by 2010, SA and other developing countries will therefore have to step up their efforts. If ineffective national leadership and AIDS denialism continue, these targets will be undermined locally and globally. And it is worrying that there are no signs of these problems abating. For example, in legal papers filed by the national Department of Health this year in the Cape High Court in a case brought by the Treatment Action Campaign (TAC) against inter alia Matthias Rath, his associates and the Government of SA for making widespread false and exaggerated claims about the medical utility of high dosages of multivitamins (claiming that multivitamins are substitutes for ARVs), the Director General of Health has reported finding no wrongdoing by Rath or his associates, and has therefore defended not taking any steps to end the widespread distribution of false information by Rath suggesting that vitamins are a substitute for ARVs. ${ }^{11}$

Therefore, despite having some of the best HIV/AIDS policies on paper and a strong legal framework for protection against unfair discrimination, confusion and ambiguity has characterised our government's response to AIDS.
While members of parliament (MPs) and senior ANC officials have privately berated such a response, none, save for two prominent ANC members, Kader Asmal (former Minister of Education and ANC MP) and Ben Turok (ANC MP), have publicly drawn themselves (albeit unwittingly) into the debate. International donors and institutions such as the WHO, GFATM, and UNAIDS have also shied away from publicly doing so. The one exception has been Stephen Lewis in his capacity as Special UN Envoy for HIV/AIDS in Africa. Lewis has repeatedly declared that the lack of leadership and political commitment in SA is undermining the regional and international struggle against HIV/AIDS. For this the Ministry of Health has unfairly attacked and attempted to marginalise him.

Regionally and internationally, SA's response is not only embarrassing but dangerous as well. This is because many developing countries look to SA for solutions and leadership.

Therefore, in my view, the ARV programme has become a comfortable hiding zone for government and in particular the denialist views of certain senior officials. Because government is paying for ARVs, no one dare criticise the pace of implementation. But we must. You see, our government may be paying for ARVs but it is doing so slowly, reluctantly and without any great vigour or creativity. In fact, it is deliberately stalling on its own programme.

\section{REFERENCE}

1. Missing the Target: Off target for 2010: How to avoid breaking the promise of universal access. Update to ITPC's AIDS treatment report from the frontlines. http://www.aidstreatmentaccess.org/itpcupdatefinal.pdf (last accessed 28 June 2006).

2. Progress Report on the Declaration of Commitment on HIV and AIDS http://www.doh.gov.za/docs/index.html (last accessed 28 June 2006).

3. South Africa Joint Civil Society Monitoring Forum: Resolutions and Minutes. $\mathrm{http}: / /$ www.alp.org.za/modules.php?op=modloadctname=Newstfile=artic eftsid=8 (last accessed 28 June 2006).

4. Letter from JCSMF dated 6 April 2006 to Kofi Annan regarding SA's Progress Report. http://dedi20a.your-server.co.za/alp/images/upload/JCSMF.UNGASS. pdf (last accessed 28 June 2006)

5. Social Cluster briefing: Parliamentary Media 10 February 2006 http://www.doh.gov.za/mediaroom/index.html (last accessed 28 June 2006).

6. Hassan F, Bosch D. Monitoring the provision of ARVs in South Africa - a critical assessment. ALP Briefing for TAC NEC. 17 and 18 January 2006, Cape Town. Available from author.

7. Republic of South Africa: Progress Report on the Declaration of Commitmen on HIV and AIDS. Prepared for: United Nations General Assembly Special Session on HIV and AIDS, February 2006. http://www.doh.gov.za/ docs/index.html (last accessed 28 June 2006).

8. A National Human Resources Plan for Health, April 2006 http://www.doh.gov.za/docs/discuss-f.html (last accessed 28 June 2006).

9. ALP and TAC. Joint Submission on A Strategic Framework for the Human Resources for Health Plan: Draft for Discussion. http://www.alp.org.za/ modules.php?op=modload\&tname $=$ News\&file=articlectsid $=261$ (last accessed 28 June 2006).

10. Hassan F. Let them eat cake - a short assessment of provision of treatment and care 18 months after the adoption of the operational plan, June 2005. Updated Second Joint Report on the Implementation of the Operational Plan for Comprehensive HIV and AIDS Care, Management and Treatment for South Africa. AIDS Law Project and Treatment Action Campaign. http://dedi20a.your-server.co.za/alp/images/upload/2nd\%20report.pdf (last accessed 28 June 2006).

11. Affidavit of T Mseleku (DG of Health). In TAC $\vee$ Matthias Rath and 11 Others Cape of Good Hope Provincial Division Case Number 12156/05. 